\title{
Future projects on water resources for a sustainable urban development: a case study of Surat city of India
}

\author{
K. A. Chauhan ${ }^{1}$, J. P. Shah ${ }^{1}$, A. M. Pingle ${ }^{2}$ \& A. K. Chauhan ${ }^{3}$ \\ ${ }^{I}$ Department of Urban Planning, CED, S.V.NIT, Surat, Gujarat, India \\ ${ }^{2}$ Department of Civil Engineering, MVPCOE, Nasik, India \\ ${ }^{3}$ Department of Civil Engineering, CKPCET, Surat, India
}

\begin{abstract}
The urban population in India has increased significantly from 62 million in 1951 to 285 million in 2001 and is estimated to grow around 540 million by the year of 2021. It would be touching $37 \%$ of the total population in next 15 years. The Indian urban population growth is nearly $41 \%$ in last decade. This directly means providing additional drinking water for around 65 million households as well as deciding on the number of administrative complexes. The city of Surat is a fast growing city and it is the $9^{\text {th }}$ largest city of India as per Jawaharlal Nehru National Urban Renewal Mission (JnNURM). The present population of Surat city is approximately 45 lacks including the floating population. The dream of achieving sustainable habitat could be possible only through a multi dimensional and inter disciplinary approach. Exploitation of natural resources along with the development of urban areas with or without the knowledge of planners is a matter of great concern in the context of sustainable development. Out of various natural resources that are exploited, the tapping of water resources and its impact on the habitat is studied in the paper. The study was conducted in and around Surat city of the Gujarat state. The futuristic projects by local government Surat Municipal Corporation (SMC) for the sustainable development of Surat is also included in accordance with what has been envisioned in the revised city development plan. The present paper focuses on planning principles and is a classic example for sustainable development in water resources planning. Keywords: water resources, sustainable development, futuristic project.
\end{abstract}




\section{Introduction}

The Millennium Development Goals created by the United Nations in the year 2000 hoped to generate an international effort to fight poverty and disease. One of the goals related to water is to reduce by half, by 2015, the proportion of people without sustainable access to safe drinking water. Currently there are over one billion people worldwide without access to potable water; the majority live in Africa and Asia. Water resource planning is essential in reversing this negative trend and developing feasible sources of water for domestic use that are aligned with local economic, social, cultural, and environmental conditions.

Urban areas vary from city to city therefore, planning must be adopted specifically to the local context and should therefore consider the fact that as the population grows and settlements increase in size, it will begin to compete with neighbouring settlements. A simplified water supply network is an important infrastructure in urban areas of developing countries [1]. The term 'sustainable development' first came to prominence in the World Conservation Union in 1980. It has achieved a new status with the publication of 'our common future', the Brudtland Report, in 1987 and has gained even greater attention since the United Nations Conference on Environment and Development (UNCED) held in Rio de Janeiro in June 1992 [2]. Of late, sustainable development has become one of those magic terms used by almost everybody though not necessarily in a proper way or in the right context. Some people believe that this concept will solve all our problems while others tend to be suspicious as to whether it really does anything meaningful. Construction activities which are imperatives for economic development is one area where tremendous exploitation of natural resources is taking place and often the deterioration caused on the environment, in the hinterlands, is left unchecked. The lack of proper water supply system, due to which direct exploitation of ground water by individual families, is another activity, which leads to the deterioration of water resources, within the urban areas.

\section{Study area}

Surat is one of the ancient cities on the Western coast of India. Surat city is located in the southern part of Gujarat state. The city lies on the bend of River Tapi, the western side of the Arabian Sea (meandering), as shown in Figure 2. This region has problematic black cotton soil. The climate of Surat city is hot and humid due to the location of the nearby sea. Due to the sea, salt water intrusion occurs. The summers are quite hot with temperatures ranging from $37.78^{\circ} \mathrm{C}$ to $44.44^{\circ} \mathrm{C}$. the maximum humidity is about $80 \%$. The rainy season is usually four months with an average rainfall of $1143 \mathrm{~mm}$. The wind is mostly from the sea towards the main city at $44 \mathrm{mt} / \mathrm{sec}$. 


\subsection{Growth trends}

In developing countries, the number of people living in towns and cities is growing rapidly both as a result of natural urban growth and because of immigration into towns and cities from rural areas. This will add significantly to the number of people living without clean drinking water. It will also cause more unemployment and poverty, widening the gap between urban rich and urban poor who lack access to a whole range of basic services besides clean water, including health care, sanitation, education, transport, adequate housing, security, information and justice.

The municipal limits in Surat have increased from $112.27 \mathrm{sq} . \mathrm{km}$ to 326.52 sq.km in the year 2006. The city has been experiencing rapid growth in population during the past four decades. The growth rates have been one of the highest in the country.

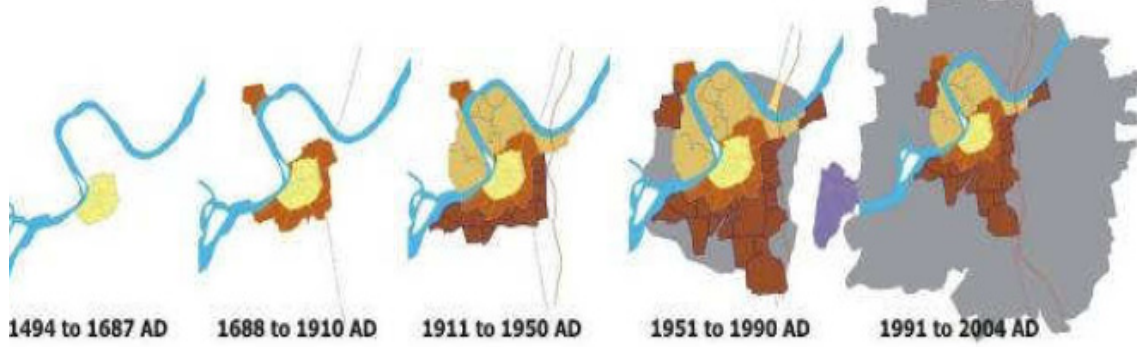

Figure 1: Growth trends of Surat city.

The high rate of growth experienced by the city over four successive decades has been a major feature in the city's growth which is shown in Figure 1, necessitating prompt responses in the supply of infrastructure. Surat has experienced a rapid population increase in the census decade. The population growth rate of Surat city is shown in Table 1.

Table 1: $\quad$ Population- growth rate for Surat.

\begin{tabular}{|c|c|c|c|c|c|c|c|}
\hline Year & $\mathbf{1 9 5 1}$ & $\mathbf{1 9 6 1}$ & $\mathbf{1 9 7 1}$ & $\mathbf{1 9 8 1}$ & $\mathbf{1 9 9 1}$ & $\mathbf{2 0 0 1}$ & $\mathbf{2 0 1 1}$ \\
\hline $\begin{array}{c}\text { Population } \\
\text { (in Lakhs) }\end{array}$ & 2.23 & 2.88 & 4.72 & 7.77 & 14.99 & 24.34 & $\begin{array}{c}45.00 \\
\text { (Est.,) }\end{array}$ \\
\hline $\begin{array}{c}\text { Growth } \\
\text { Rate\% }\end{array}$ & 30.18 & 29.05 & 63.75 & 64.65 & 93.00 & 62.38 & $\begin{array}{c}57.38 \\
\text { (Approx) }\end{array}$ \\
\hline
\end{tabular}

\subsection{Overview of SMC water supply}

With the increase in area and population, the water supply served has decreased from $97 \%$ to $32.49 \%$ of its total populated area and from $95 \%$ to $79 \%$ of its population. The new area, which is not served, is mostly made up of agricultural land within the SMC limits. Under JnNURM water supply project has already been sanctioned and the works are under implementation. Apart from these the 


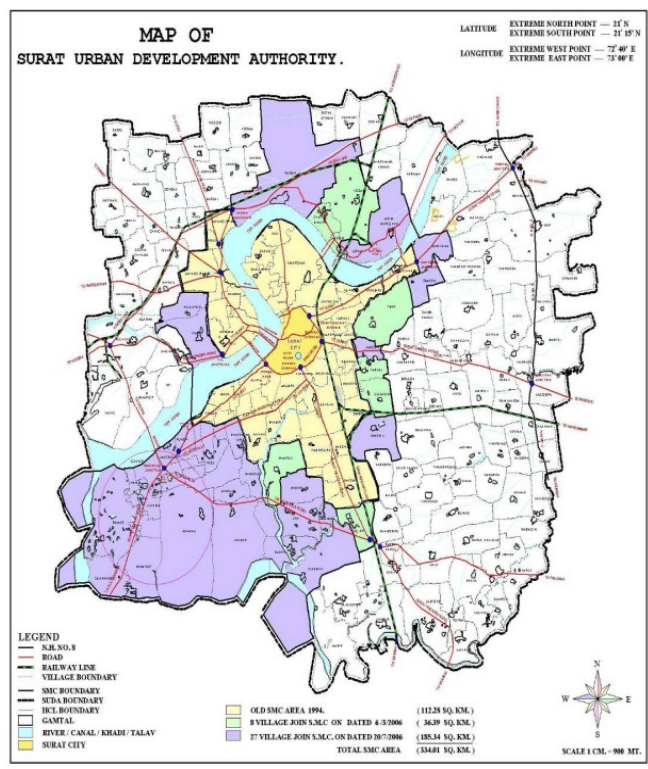

Figure 2: $\quad$ Surat urban area.

areas still to be covered with piped water supply are parts of Nana Varachha, Varachha, Bamroli, Adajan and a part of Limbayat, Jahangirpura- Jahangirabad, Ved, Dabholi, etc. These areas are at presently being served by water tankers owned by SMC [3]. The work of lying of pipeline network has already been started in these places, which will make 100 percent population and populated area coverage of the city under water supply network, a reality in the coming years.

The corporation also caters to the water supply demand of the floating Population. At present gross $175 \mathrm{lpcd}$ is being supplied to the population of the city. Due to the construction of Rander Water Works, water supply pipeline grid has been formed, which will ensure that there would be no disruption of water supply in any part of the city.

Table 2: $\quad$ Water supply - area and coverage.

\begin{tabular}{|c|c|}
\hline Total area of Surat (sq. km) & 326.515 \\
\hline Area covered by piped water supply (Sq.km) & 108.92 \\
\hline \% of area served & 32.49 \\
\hline Population coverage (lakhs) & 32.47 \\
\hline \% of total population served & 78.54 \\
\hline Total water supply capacity (ground and surface) (MLD) & 918 \\
\hline Total water supplied (ground and surface) (MLD) & 760 \\
\hline Gross daily supply (lpcd) & 175 \\
\hline
\end{tabular}


Table 3: $\quad$ Present yield of water works.

\begin{tabular}{|c|c|c|c|c|c|}
\hline Water Works & Varachha & Sarthana & Katargam & Rander & $\begin{array}{c}\text { Total Present } \\
\text { Yield }\end{array}$ \\
\hline $\begin{array}{c}\text { Present Yield } \\
\text { (in MLD) }\end{array}$ & 30 & 280 & 220 & 150 & 680 \\
\hline
\end{tabular}

\subsection{Future demand of water}

Total Water Demand Preliminary forecasted figures of water demand up to year 2041 have shown in the Figure 3. From the study its derived that by 2026 water demand will be about 1800 MLD and by 2041 water demand will be about 2400 MLD [4]. The city has been divided into six water zones. North, West, Central, East, South and South-West. In order to meet the requirements of the year 201121 additional distribution stations are proposed at Singanpore, Ved. Rander, Jahangirpur, Jahngirabad, Limbayat, Athwa, Althan, Sagarampura, Udhana and Bhestan. The demand for Water supply of different zone shown in the Table 4.

\section{WATER DEMAND UP TO YEAR 2041}

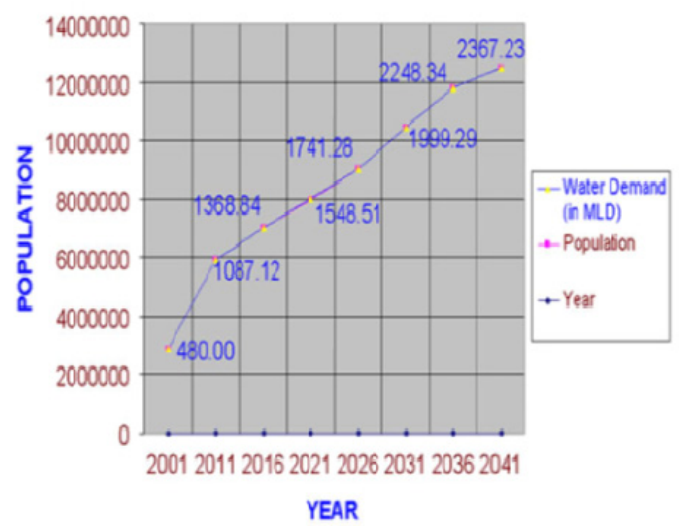

Figure 3: $\quad$ Water demand and supply up to 2041.

Table 4: $\quad$ Water demand zone wise.

\begin{tabular}{|c|c|c|c|c|c|c|c|}
\hline Zone & \multicolumn{7}{|c|}{ Demand (MLD) } \\
\cline { 2 - 8 } Year & West & S-W & North & Central & South & East & Total \\
\hline 2001 & 79 & 64 & 107 & 137 & 138 & 145 & 670 \\
\hline 2011 & 131 & 118 & 162 & 151 & 195 & 183 & 940 \\
\hline 2021 & 180 & 167 & 239 & 165 & 240 & 219 & 1210 \\
\hline
\end{tabular}




\section{Design input parameters}

\subsection{Average household size}

This is multiplied by the number of houses in an area to determine the design population in that area or contributing to the water leg. Results from the social survey will provide information on the average household size in the area to be provided with water. The Surat city has average household size considered 4.2.

\subsection{Average per capita water consumption}

This is multiplied by the design population for any area to calculate the total amount of water used during a typical day. Information on average per capita water consumption may be available from meter readings. For Surat city the average per capita water consumption is $175 \mathrm{lpcd}$ [5].

\section{Design: over-riding parameters}

\subsection{Minimum water diameter}

It is necessary to specify a minimum water diameter. There is no theoretical reason why the minimum water diameter should not be $100 \mathrm{~mm}$. Every effort should be made to introduce appropriate standards, but it may be necessary to accept a higher minimum diameter than is absolutely necessary. In such circumstances, it is best to seek what is possible rather than the ideal.

\subsection{Minimum flow}

The recommended norms as per Town and Country Planning Organization for per capita supply are $135 \mathrm{lpcd}$ minimum, avg. $180 \mathrm{lpcd}$ and maximum $220 \mathrm{lpcd}$.

\subsection{System sustainability}

The long-term sustainability of simplified water systems can be ensured by:

A good partnership between the communities served by simplified water system and the water supply authority, Good design, Good construction, Good maintenance, an adequate but affordable, tariff structure.

\section{Adaptive planning for water}

The Surat city has undergone a vast change after the expansion of area in 2006. With the increase in area population and hence its water requirement has also increased drastically. Also for the water supply to industries has become an issue to SMC. The water intake presently for the whole city is done from only natural source that is Tapti River. By using motives of national water policy SMC has decided futuristic projects to fulfil future demand of water. E.g. Rubber Barrage dam, Kakrapar pipe line project, and river front development. 
Present National water policy:

- To maximize water conservation

- To maximize ground water recharging

- To prevent pollution in water

- To prevent salinity intrusion in ground water

\subsection{Rubber barrage dam}

In the Surat municipal corporation budget 2010 it is decided to allot Rs. 120 crore for the construction of Rubber Barrage Dam. SMC will build a 580 metre wide air balloon structure barrage dam between Umra-PIplod at a cost of Rs 120 crore to create a 10-km-long sweet water lake in Tapi [6]. The Local Government has decided to go ahead with this long-pending project after receiving the irrigation department's advice that the rubber barrage structure was most suited for the city. This technology has been successful in the US, Japan, Australia and some European countries, but surprisingly since 1957 has not been used anywhere in India as shown in the Fig. 4 and salient features of Barrage dam shown in Table 5.

Objectives of Rubber Barrage Dam Project:

- Long term planning for water supply requirement

- To prevent tidal silting

- To prevent river pollution

- To conserve the maximum excess water spilled released from Singapore weir

- To prevent salinity intrusion in ground water

- To develop water sports place

- To prevent encroachment in the river bed

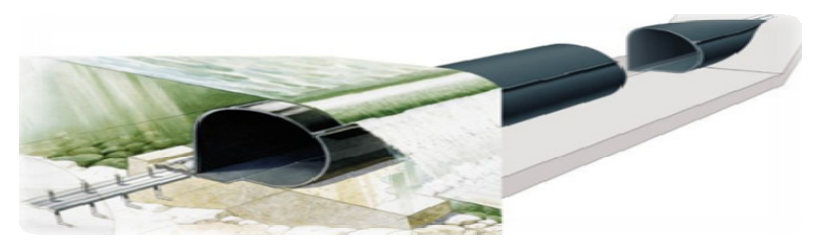

Figure 4: Rubber barrage dam.

Table 5: $\quad$ Salient features of the barrage dam.

\begin{tabular}{|ll|ll|}
\hline \multicolumn{2}{|l|}{ Reservoir length } & 10 & $\mathrm{~km}$. \\
\hline Avg. & Width & 500 & $\mathrm{mt}$. \\
\hline Max. & Depth & 6 & $\mathrm{mt}$. \\
\hline Min. Depth & 2 & $\mathrm{mt}$. \\
\hline Barrage dam length & 580 & $\mathrm{mt}$. \\
\hline FRL of barrage dam & 4.0 & $\mathrm{mt}$ \\
\hline
\end{tabular}




\subsection{Kakrapar to Surat water supply pipeline project}

The river has gone polluted with more industrial wastes flowing illegally into it. Keeping in mind the future water requirements of Surat city, local body has taken a decision on fulfilling it from Kakrapar weir. This would be a project from Kakrapar weir to Surat having a total pipe length of $58 \mathrm{~km}$. Due to the revised area and population scenario, revision in existing Master Plan of water supply, based on earlier city limit, became necessary [7]. Total project cost will be 25 crores, ductile iron pipe will be used.

Design consideration:

- $\quad$ The pipeline should be as short in length as possible.

- The chance of leakages is more so maintenance at various points is required.

- The pressure needs to be maintained as that would create damage to the pipes and further lead to maintenance problem.

Also the pipeline should have minimum crossing over from river. It can be seen from the Figure 5 that the distance approximately comes to around 35 to 40 $\mathrm{km}$ if the pipeline is connected via Sampura and further following NH 8 leading to Varachha which is shown in Fig. 5. The red line shows water supply from Kakrapar to Surat taken along the river and then along the NH to Varachha water works. The ultimate aim of fulfilling demand can be achieved.

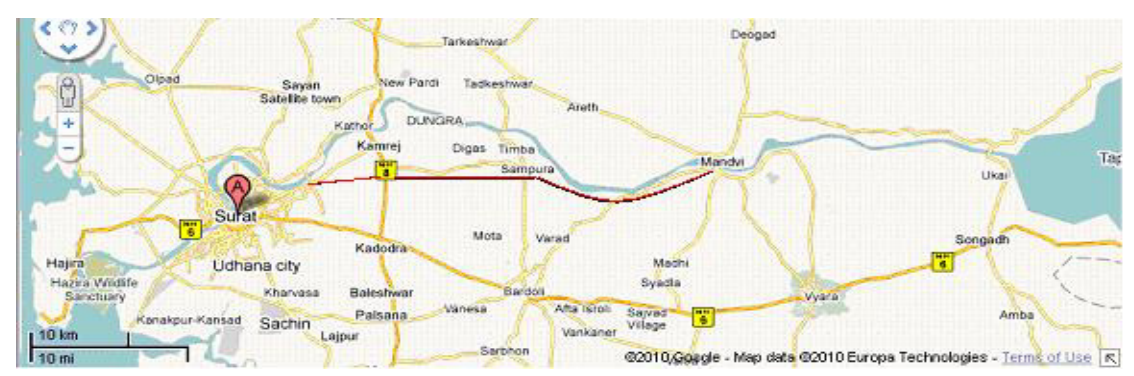

Figure 5: $\quad$ Pipeline proposed for water supply.

\subsection{River front development}

- The whole derivation out of this link itself gives us our identity

- An attempt to revive very strong link from our past which is somehow being lost in the modern world

- $\quad$ Revitalize the stretch which hold very strong reference point for the identity of the city of glory

- Uniqueness in the Ovara - a point where the city gets chance to spend some time on their own with the purest form of element that is water

- $\quad$ Providing proper amenities and infrastructure for religious and festival occasions 
- Deal with issue not only permitting to the physical landscape but also try to imbibe the ethnic identity.

- Present scenario of Tapi River Front shown in Figure 6 and how the future scenario of Tapi River Front will look is shown in Figure 7.

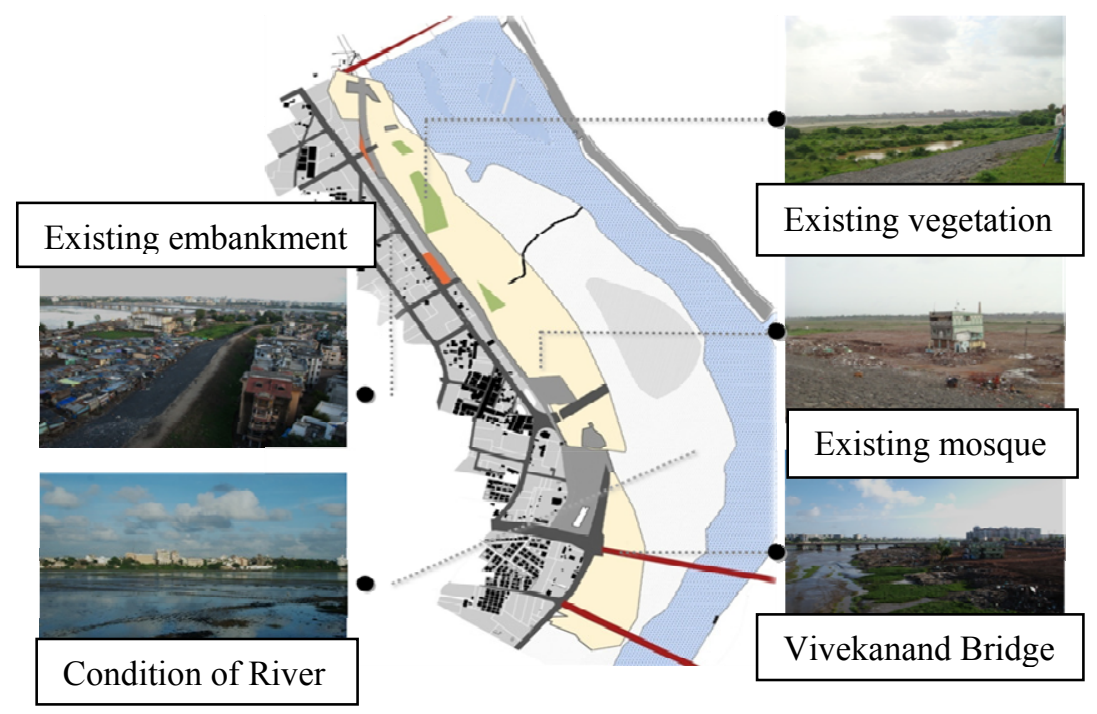

Figure 6: Existing scenario of Tapi river front.

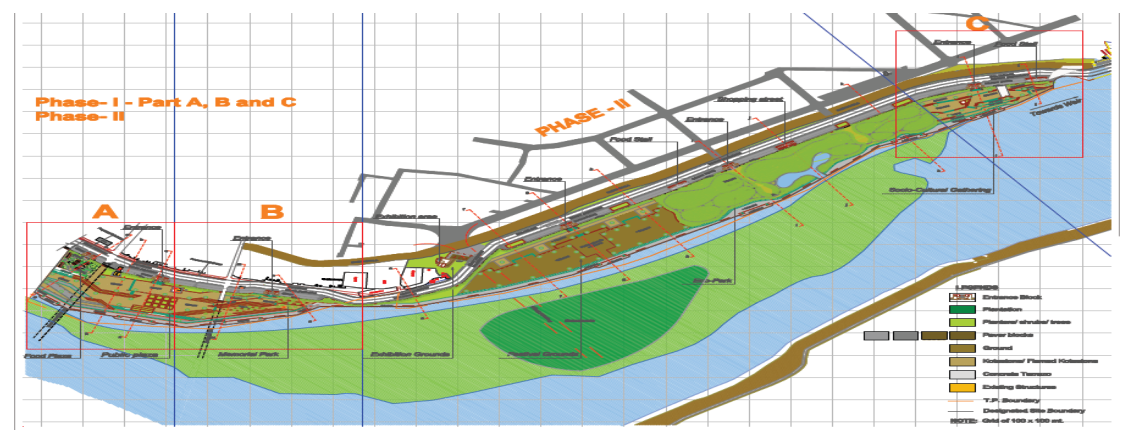

Figure 7: $\quad$ Future scenario of Tapi river front.

\subsection{Sustainability of the Kakarapar-Surat pipeline project}

- Distribution to villages will be possible by this project;

- More population will be cover under this project;

- Varachha treatment plant will get the raw water and so the capacity of this plant will be increased by large account. 


\subsection{Sustainability of river front development}

- Issues of connecting road network;

- Present land use is backing towards River;

- Uneven and uncontrolled character of road edges;

- Lack of pedestrian friendly infrastructure;

- Preservation of River as a valuable natural resource and thereby improving quality of natural environment;

- Value addition to existing land use of open spaces and there by promotion of recreational hub.

\subsection{Future project benefits}

It will not only benefit the social and economic status of the urban area, it will also improve the environmental condition of the watershed area.

\subsubsection{Environmental benefits}

One of the main goals of urban water supply planning is to ensure that the negative environmental impacts of implementing a water source are minimized.

- Proper Rubber Barrage Dam structures reduce the erosive behavior of high velocity water travelling through streams;

- Running a simulation to develop ideal storage capacities for Rubber Barrage Dams minimizes the encroachment on the surrounding land;

- Properly sizing rainwater harvesting storage units minimizes the amount of natural resources used for construction;

- Finding feasible technical solutions other than drilling deep boreholes improves groundwater conditions about 75 sq.km areas;

- Domestic waste will be minimized, recreation land will be generated, aesthetic view will be more expressive, protection to water body will be provided.

\subsubsection{Social benefits}

The following list describes the social benefits of involving the local population in the decision making process.

- Develops the capacity of the local Government to manage their own systems;

- Develops the leadership and communication skills of members of the community; and

- Provides employment to landless people, increasing their social status within the community;

- Improved water supply and quality minimizes the diseases caused by contaminated water;

- Population coverage will be around 8 lakhs of SMC in Domestic use, 0.5 lakhs in Agricultural activity of Surat Urban Development Authority (SUDA)region while 0.5 lakhs population and for the industrial use of Hajira Area Development Authority (HADA) region. 


\subsubsection{Economic benefits}

Effective watershed management projects provide countless benefits for improving the standard of living for the resource-poor and disadvantaged sections of the community. Also, improving the water resources of the targeted regions increases the productivity of local farmers, hence increasing the crop profitability.

- The total costs of implementing potential waters sources can be compared to determine an economically viable source;

- The costs of sustaining potential water sources through operation and maintenance can be estimated for feasibility purposes;

- $\quad$ Physically these all projects will cover about 125 sq.km area of SMC, 25 sq.km of Surat Urban Development Authority (SUDA) and 50 sq.km of Hajira Area Development Authority (HADA).

\section{Conclusion}

Water has always been viewed as an abundant resource that is inherently sustainable in nature. This prevalent mentality has persisted to hinder the process of taking measures to preserve this vital resource. Even though water is used for many purposes, the most important catalyst for change is the knowledge that humans need water to survive. Watershed management projects are ideal in theory as well as Rubber Barrage dam, Kakrapar-Surat pipeline project and Tapi River Front project are already been approved by the State Government Authority. After the completion of all these projects around one fourth of the Surat city population will be covered for the different use as Domestic, Industrial and Agriculture purpose. So the ultimate aim of fulfilling demand of water can be achieved efficiently.

\section{Acknowledgements}

The authors are very grateful to all the policy makers and Technical officers of SMC for providing data and valuable guidance regarding the futuristic project work of the Surat city. Special thanks are also extended to Dr. S. M. Yadav for improving the manuscript substantially.

\section{References}

[1] Gadgil, A. (1998). 'Drinking water in developing countries', Annual Review of Energy and the Environment, Vol. 23, pp. 253-286.

[2] Bureau of Indian Standards (BIS), Government of India (1991). Drinking water (first Revision), IS number 10500, New Delhi.

[3] Surat Municipal Corporation, City Development Plan-2006, Surat, Gujarat, India.

[4] Amol Pingle, Dr. K.A. Chauhan (2011) 'Graduate Report on Water Supply Network of Surat city', SVNIT, Surat, Gujarat, India. 
108 Sustainable Development and Planning V

[5] Department of Drinking Water Supply, Government of India (1986). Guideline for implementation of accelerated rural water supply program, New Delhi.

[6] CSWCRTI, Central Soil and Water Conservation Research and Training Institute (1982). 25 Year Research on Soil and Water Conservation in Southern Hilly High Rainfall Regions, ICAR Publishing, Udhagamandalam.

[7] Jagruti Shah, Gaurang Desai, Dr. K.A. Chauhan (2011) 'Graduate Report on Futuristic Development project of Surat city’, SVNIT, Surat, Gujarat, India. 